\title{
PARA UMA COMPREENSÃO DO SAGRADO NO PROTESTANTISMO BRASILEIRO EM SUA EXPRESSÃO CONTEMPORÂNEA*
}

\author{
Understanding holy in Brazilian protestantism in its \\ contemporary expression
}

\author{
Uipirangi Franklin da Silva Câmara** \\ Edilson Soares de Souza***
}

\begin{abstract}
RESUMO
Esse artigo trabalha a possibilidade de contribuir com observações importantes para abordagem do Protestantismo no Brasil por outros grupos de saber, não necessariamente conscientes de certas peculiaridades do protestantismo, principalmente quando de uma abordagem do sagrado por esse grupo. Dessa maneira, propõe como um eixo de abordagem um diálogo entre a História e as Ciências da Religião, privilegiando a abordagem de uma sociologia compreensiva. O texto pretende articular transmissão religiosa, memória e identidade no Protestantismo Brasileiro partindo de Maurice Halbwachs e Paulo Barreira como referenciais teóricos principais.

Palavras-chave: sagrado; protestantismo brasileiro; história; ciências da religião; memória e identidade.
\end{abstract}

\footnotetext{
ABSTRACT

This article was built to create a possibility to discuss about the Protestantism in Brazil. And it qualifies other groups of education to have knowledge about peculiarities of Protestantism. In this way we

* Esse artigo é fruto de diálogos articulados com o professor Edílson Sousa e de pesquisas para a dissertação de Mestrado do Prof. Uipirangi Câmara defendida na UMESP em 2003. Os autores são

** Doutorando em Ciências da Religião pela Universidade Metodista de São Paulo, pesquisador do NUPPER e professor da Faculdade Teológica Batista do Paraná.

*** Mestrando em História pela Universidade Federal do Paraná, psicólogo clínico com formação em sistêmica e pesquisador do NUPPER.
} protestantes de tradição Batista. 


\begin{abstract}
have a dialogue between History and Religion Science consider ing it as an approaching support, privileging the study of a comprehensive sociology. The text intends to articulate religious transmission, memory and identity in the Brazilian Protestantism having Maurice Halbwachs and Paulo Barreira as main theoretical references.
\end{abstract}

Key-words: holy; Brazilian protestantism; history; religion sciences; memory and identity.

É cada vez mais reconhecido o fato de que o fenômeno religioso em suas múltiplas manifestações no Brasil tem influenciado uma série de abordagens teóricas e que, não poucas vezes, uma série de deduções equivocadas têm surgido por falta de algum conhecimento dos meandros e nuanças desse campo, sobretudo quando se trata do protestantismo e de seus vários representantes no Brasil. Para tentar contribuir com uma possibilidade mais segura de abordagens, esse artigo pretende propor a transmissão religiosa desenvolvida na prática protestante brasileira como um caminho teórico mais propício ao diálogo com outros campos do saber, principalmente quando de uma abordagem que pretende entender as articulações desse grupo quanto ao sagrado.

\title{
Identidade e transmissão religiosa
}

As sociedades contemporâneas têm apresentado um quadro pluralista na questão de formas de expressão do sentimento religioso. Diante desse pluralismo, não é precipitado supor que essas formas de expressão religiosa precisam articular um mecanismo de sobrevivência e de transmissão de suas características. O Protestantismo Brasileiro, nas suas muitas faces, não está imune a esse fenômeno, o que impõe a ele, como representativo de formas de expressão do sentimento religioso, uma articulação, também muito complexa, para sobreviver. No caso do protestantismo, se observa que uma série de mudanças tem acontecido no âmbito da transmissão religiosa. Essa transmissão religiosa pode ser definida como o conjunto de atividades dinamizadas pelo poder à reprodução do sistema religioso. E 
no caso do protestantismo é importante compreender que a transmissão religiosa tem sofrido modificações por uma de suas faces - o Pentecostalismo:

As mudanças na transmissão religiosa protestante na América Latina são evidenciadas pelo pentecostalismo. Isso porque o pentecostalismo abre mão da tradição religiosa para construir sua legitimidade, desinteressando-se pela tradição e concentrando recursos na promoção de experiências religiosas fortes, embora efêmeras. ${ }^{1}$

A transmissão religiosa tem o seu valor metodológico por permitir uma avaliação da eficácia na reprodução do sistema religioso. O que, numa análise preliminar do pentecostalismo como face do protestantismo, nos remete já uma grande questão: como ele consegue sobreviver, numa sociedade em constantes transformações, abrindo mão da tradição e articulandose a partir de experiências efêmeras? Avaliar as possíveis "engrenagens desse mecanismo é importante para análise do que, no reverso dessa questão, as expressões mais tradicionais"² estão fazendo para manter-se no mesmo quadro de pluralidade e mudanças aceleradas. Paulo Barreira sustenta a hipótese de que o pentecostalismo contemporâneo está determinando uma transformação radical no sistema de transmissão religiosa. Para ele, é possível verificar que a eficácia da transmissão não está mais na fidelidade à tradição fundadora, e sim na produção de um "fiel” de identidade religiosa precária. As identidades religiosas contemporâneas desenvolvem-se em torno das emoções, em detrimento da catequese que outrora caracterizava o Protestantismo. Passou-se, segundo Barreira, da legitimidade pela tradição à legitimidade pela emoção. ${ }^{3}$

Para Barreira, as identidades religiosas da atualidade manifestam formas mais fluidas. Decorre-se, então, o fato de que essas formas desa-

1 BARREIRA, Paulo Rivera. Tradição, transmissão e emoção religiosa - rociologia do protestantismo contemporâneo na América Latina. São Paulo: Olho D’Água, 2001. p.17.

2 No âmbito desse artigo, tradicional deve ser compreendido pelo viés de presença histórica, ou seja, os grupos mais antigos cronologicamente, a exemplo dos Presbiterianos, Metodistas, Batistas e Luteranos.

3 BARREIRA, op. cit., p. 18. 
fiam conceitos chaves como: rito, fiel, identidade e pertença religiosa. ${ }^{4}$ Nessa perspectiva, o culto coletivo torna-se o espaço e o tempo privilegiados da transmissão religiosa protestante. Daí a relevância de se avaliar o espaço do culto coletivo, além das implicações com o sagrado, como marco teórico na análise da transmissão religiosa.

\section{Memória e transmissão religiosa}

O fenômeno da transmissão religiosa não pode prescindir dos estudos feitos por Maurice Halbwachs. Ao introduzir Halbwachs no universo da transmissão religiosa do protestantismo no Brasil, especificamente do pentecostalismo, Paulo Barreira dá um passo fundamental e de vanguarda na proposta de analisar os fenômenos da religião, mudando o foco da ênfase da Sociologia Clássica na transmissão do Poder para a transmissão religiosa. (Isso se torna significativo, sobretudo no Brasil.)

Maurice Halbwachs, discípulo de Emile Durkheim, segunda geração, formado na tradição Bergsoniana, distancia-se deste ao se opor ao conceito de que a memória é conservação do passado. Para ele, é fundamental entender a memória individual na sua inter-relação com o que chama de quadros sociais da memória. Não crê que a memória seja uma tábula rasa ou que esteja fechada em si mesma. Essa sua compreensão o leva a estabelecer toda uma teoria do conhecimento da memória. Maurice Halbwachs, em seus estudos, apontou para a fragilidade da memória religiosa e, mesmo não encontrando neles uma teoria mais desenvolvida sobre o fenômeno religioso, sua maior contribuição foi a de abrir caminhos para o estudo da memória religiosa. Isso justifica a sua escolha nessa pesquisa, seguindo o fio condutor proposto por Barreira em sua prototeoria da transmissão religiosa na América Latina.

A Sociologia, desde o final do século passado, conforme observa Barreira, tem revisado seus postulados sobre a natureza das relações sociais das formas de representação e de a formação de identidades na sociedade

4 BARREIRA, op. cit., p. 20. 
moderna, principalmente pelo fato da sociedade moderna ser caracterizada pela mudança acelerada, comunicação imediata, pela circulação generalizada de bens, capitais, pessoas, saberes e símbolos. Nesse cenário é que se apresentam as questões de tempo, memória e esquecimento. ${ }^{5}$ Analisando a diversidade dos comportamentos, tendências e sentimentos pelos quais as pessoas classificam a si mesmas e às outras dentro da escala social, formula-se a hipótese de que o homem caracteriza-se essencialmente pelo seu grau de integração no tecido das relações sociais. ${ }^{6}$ A memória coletiva, na perspectiva da sociologia, é essencialmente uma reconstrução do passado, adaptando a imagem dos fatos passados às crenças e às necessidades espirituais do presente. Aquilo que foi na origem passa a ser secundário, senão totalmente inútil, porque a realidade do passado não está mais lá, como se fosse um modelo imutável ao qual é preciso se confirmar. ${ }^{7}$

Halbwachs defende o primado da memória coletiva sobre a individual e define a memória como uma reconstrução do passado em função das necessidades do presente. ${ }^{8}$ Entendendo a memória como a trama das identidades individual e coletiva, Halbwachs chega à conclusão de que a memória é uma condição de identidade dos grupos e das pessoas. Por conseguinte, a preservação da memória é condição da identidade e da unidade de um grupo humano, e a retomada do passado um fato de emancipação social. Uma sociedade sem memória perde a identidade e torna-se incapaz de encarar o futuro. ${ }^{9}$ É possível entender o desenvolvimento das idéias de Halbwachs a partir de uma parábola sobre uma jovem escrava encontrada perdida num bosque sem saber quem é e de onde vem. Não guarda nenhuma lembrança de sua infância e dos poucos detalhes que lembra destaca a travessia de grandes extensões de mar por duas vezes e que ficava muito comovida quando lhe mostravam imagens e produtos de esquimós. A visualização dessas imagens e produtos faz com que ela se aproprie de um mínimo de identidade pessoal, lembrando-se que era escrava de uma senhora que gostava muito dela e o patrão, que não a suportava, obrigou-a a

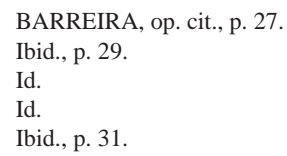


embarcar. ${ }^{10}$ Essa parábola é usada por Halbwachs para demonstrar que a memória depende significativamente do contorno social. Ela não é ativada isoladamente, mas apóia-se no grupo social implicado nas experiências lembradas. ${ }^{11}$ É do grupo que recebemos a confirmação de nossas lembranças. São as testemunhas da nossa vivência que freqüentemente nos permitem lembrar e validar nossas recordações: as referências comuns nos guiam e ativam nossa atividade memorial. ${ }^{12}$

A memória, para Halbwachs, constitui uma força simbólica que fornece a possibilidade de construção de uma totalidade de sentido. Nesse caso, a memória seria um marco simbólico:

A pluralidade de jogos da memória reproduz a variedade de pertenças que definem a inserção social na sociedade. Em cada memória especial há uma subdivisão em muitas memórias menores. Quem é protestante pertence simultaneamente à tradição da Reforma, à memória institucional da denominação e à pequena memória de sua paróquia ou igreja local. Há também as experiências pessoais ou familiares, no caso de uma família protestante. ${ }^{13}$

A questão levantada por Paulo Barreira quanto ao ambiente de pluralidade de memórias é bastante significativa. Como, diz ele, é possível diante dessa pluralização de memória ter uma coesão formando uma memória comum? ${ }^{14}$

O grande desafio à proposta de Halbwachs é a atomização da memória nas sociedades modernas, pois as pessoas pertencem a cada vez mais grupos, os quais se subdividem em outras ramificações. A pluralidade de memórias preexistentes na sociedade tradicional (grupo religioso, doméstico, familiar, rural) é agora muito mais intensa. ${ }^{15}$

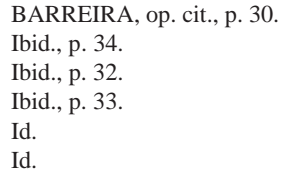


As identidades individuais, diante dessa pluralidade, não são mais exclusivas, são frágeis, têm uma duração curta e sua constituição não depende do apoio das grandes tradições:

A pluralização extrema prende o indivíduo a pequenas memórias cada vez menos coesas entre si. A pertença individual aos grupos torna-se cada vez mais funcional e técnica e cada vez menos vinculada à memória orgânica e organizadora. ${ }^{16}$

A partir de outra metáfora, onde surge uma orquestra em funcionamento, Halbwachs propõe a possibilidade da constituição de uma memória comum a um código comum:

Numa apresentação de orquestra as pessoas podem conhecer a melodia, reconhecê-la se já a conhecem, reproduzi-la, reconstruí-la segundo seu gosto. Seria impossível verificar a melodia sem um grupo de músicos conduzindo-a segundo uma formulação codificada numa linguagem musical, a escritura. Há um acordo prévio sobre o significado dos signos musicais. Esses últimos não têm sentido para quem não tem nas mãos uma partitura, mas ignora a existência da orquestra: seu sentido se revela no conjunto do qual fazem parte no momento da interpretação. ${ }^{17}$

A metáfora da orquestra sugere uma reflexão sobre o sujeito na sociedade, já que uma sociedade mantém um conjunto quando cada pessoa que toca um elemento da partitura reconhece, através dessa linguagem musical comum, o meio de verificação da melodia. ${ }^{18}$ Cada grupo particular articula-se em torno de um quadro social que engloba linguagem, tempo e espaço. Esse quadro social não pode ser considerado isoladamente. A linguagem compõe (constitui) o quadro social da memória e deve ser considerada parte do quadro social de cada grupo particular:

16 BARREIRA, op. cit., p. 33.

17 Ibid., p. 34.

18 Id. 
Os músicos têm suas lembranças de notas, signos, regras, lugares e pessoas com as quais escutou ou interpretou pela primeira vez certa melodia. Essas recordações permanecem nele, pois fazem parte do grupo no qual ele as adquiriu; elas conservam-se numa memória coletiva que se estende (no espaço e no tempo) tanto quanto a sociedade ou grupo ao qual pertencem. ${ }^{19}$

Essa perspectiva nos remete à conclusão de que não há uma memória pura, individual, senão numa construção de relacionamentos coletivos: "o ritmo é um produto da vida em sociedade, um individuo absolutamente só não saberia inventá-lo”. ${ }^{20}$ Nesse contexto surge uma outra memória que perpassa toda a sociedade: é a memória cultural. A análise da memória, no caso dos músicos, permite uma transferência desses conceitos ao teatro e à Igreja, sendo possível uma descrição da mesma memória coletiva, tanto no primeiro caso quanto nos demais, utilizando, ainda, o recurso da metáfora, Halbwachs introduz a imagem do solitário em Londres, e agrega aos seus conceitos uma outra dimensão: Corrente de Pensamento. Os indivíduos, mesmo que sozinhos, são interligados a correntes de memórias, conferindo, mesmo na ausência de outros, uma memória coletiva:

Chego pela primeira vez a Londres e caminho pelos mesmos lugares várias vezes, acompanhado por pessoas diferentes. Um arquiteto chama minha atenção para os edifícios, para suas proporções e disposição. Com um historiador, aprendo que tal rua foi traçada numa determinada época, que em tal casa nasceu um homem muito conhecido e que aconteceram aqui e acolá incidentes notáveis. Acompanhado por um pintor eu sou sensibilizado pela tonalidade dos parques, pela aparência dos palácios e igrejas, pelos jogos de luz e sombra nos muros e fachadas de Westminster, do templo sobre o Tâmisa. Com um comerciante vou às ruas populares da cidade, vejo lojas e livrarias. Mesmo que eu não tenha caminhado ao lado de nenhum desses homens, será suficiente ter lido descrições da cidade - feitas a partir desses diversos pontos de vista -, ter seguido as recomendações de alguém ou ter revisado a planta

19 BARREIRA, op. cit., p. 34.

20 Id. 
da cidade. Suponha-se que eu caminhe totalmente só. É possível dizer que dessa caminhada eu só guardarei lembranças individuais relacionadas a mim? A solidão é apenas aparente: ao passar por Westminster pensei naquilo que meu amigo historiador dissera ou em algo que eu lera. Atravessando uma ponte, eu observei o efeito de perspectiva sobre o qual meu amigo pintor falara ou que desenhara. Através do pensamento, eu me recoloco nos diferentes grupos de que eu fiz parte. Outras pessoas compartilharam lembranças comigo e me ajudaram a recordar; é por meio das lembranças que eu me remeto aos meus interlocutores e adoto provisoriamente o seu ponto de vista. $^{21}$

Ao agregar o conceito de correntes de memórias à memória coletiva, Halbwachs muda o seu foco para uma análise que tem seu fundamento não mais nos grupos reais, mas no que ele vai chamar de memória cultural. Numa observação de relatos de peregrinações à terra santa, Halbwachs percebeu que os relatos não se associavam ao que pôde se perceber depois que a Igreja tinha formulado uma tradição a respeito desses lugares. Numa comparação a outros relatos, agora com a tradição já formulada, ele percebeu que a opinião dos indivíduos na verdade eram crenças de grupos, fiéis, ingênuos e crédulos. ${ }^{22}$

A partir dessas constatações, Halbwachs chega à conclusão que as tradições são reconstruções geradas pela necessidade do presente. A memória religiosa vai apresentar um princípio que pode ser resumido da seguinte maneira: "uma verdade, para se fixar na memória de um grupo, deve apresentar-se sob a forma correta de um acontecimento, de uma figura pessoal ou de um lugar”. ${ }^{23}$ Segundo Paulo Barreira, diante dessas formas de verdade, apenas o lugar tem maior possibilidade de se apresentar de maneira concreta. Isso porque as pessoas e acontecimentos são passageiros, podem ser imitados, no entanto não se repetem jamais:

As pessoas não são instantâneas como os acontecimentos; durante o tempo de vida, elas podem contribuir com seus

21 HALBWACHS, 1997, p. 52; BARREIRA, M., p. 36.

22 BARREIRA, op. cit., p. 37.

23 Ibid., p. 39. 
testemunhos para a fixação de uma lembrança. Os lugares permanecem oferecendo à memória certa estabilidade. É possível voltar ao lugar dos acontecimentos ou ao lugar onde as pessoas estiveram e encontrar o mesmo quadro espacial. ${ }^{24}$

Todo grupo que pretende solidificar-se precisa articular-se num espaço comum. Ou seja, o território é indispensável para garantir a estabilidade de qualquer grupo, mas também é necessário que esse espaço seja partilhado no tempo. Uma transformação desse lugar de forma representativa, segundo Paulo Barreira, vai implicar para o grupo em novos desafios para sua memória. ${ }^{25}$ Para Halbwachs, o conceito de espaço social só existirá no tempo, na durabilidade e na permanência:

O grupo religioso, mais que outros grupos, precisa se apoiar sobre um objeto, sobre qualquer parte da realidade que dure, porque ele mesmo pretende não mudar, enquanto que em torno dele todas as Instituições e costumes se transformam e as idéias e experiências se renovam. Enquanto que os outros grupos se preocupam em persuadir seus membros de que suas regras e ordenanças permaneçam iguais por determinado período, sempre limitado, a sociedade religiosa não pode admitir que ela não seja hoje tal como foi na sua origem, sem que ela tenha que mudar no futuro. ${ }^{26}$

O grupo religioso para se sustentar precisa necessariamente acreditar em suas origens e tradições. Precisa preservar a ilusão de não-mudança, enquanto tudo muda em torno dele: “A materialidade dos lugares sagrados é ilusória, pois a grande maioria dos fiéis não pode nem precisa visitálos para certificar-se de sua existência. É suficiente imaginá-los, vê-los representados nos locais de culto e saber da sua permanência”. ${ }^{27}$ Paulo Barreira sustenta a hipótese de que o protestantismo, avesso a imagens, conseguiu manter a ilusão de não ter mudado. Fez isso construindo caminhos alternativos, como a fidelidade ao texto sagrado, considerado imutável (foi

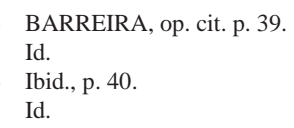


um deles). ${ }^{28}$ Diante de uma pluralidade social, a estabilidade e o futuro de toda tradição só sobreviverão numa fidelidade às origens ou numa nova articulação:

\begin{abstract}
Nas sociedades em mutação (e todas mudam), a tradição enfrenta o dilema de fidelidade às origens. A identidade religiosa deve ser mantida ou adaptada às exigências do presente para que a tradição sobreviva. A tradição religiosa só o faz transformando-se, esquecendo seus princípios. ${ }^{29}$
\end{abstract}

Os conceitos impostos pelas demandas atuais do mundo moderno em que as religiões se inserem são sintetizados juntamente com os ritos e crenças passados que não desaparecem pelo pensamento coletivo. Nesse caso, a religião integra o passado ao presente porque ela só se renova remetendo-se, mesmo que ilusoriamente, a suas origens:

Numa sociedade mutável, a religião transforma-se e tem como função relacionar o novo com o passado e incorporar esse último às novidades. A mudança social ameaça a coerência. Para continuar existindo, uma sociedade depende tanto da transformação quanto da continuidade. Eis o paradoxo de toda sociedade viva. Quanto mais ela muda, mais precisa referir-se ao passado e quanto mais o passado aparece no presente, mais é necessário colocá-lo como ponto de referência. ${ }^{30}$

A memória do grupo religioso é, para Halbwachs, uma memória conflitiva. Para se afirmar, essa memória precisa impedir que outras memórias se formem ou se desenvolvam ao seu redor. Ao mesmo tempo, essa memória incorpora elementos de fontes variadas e distintas. A religião reelabora o sentido de existência, de mundo, colocando-o dentro de códigos compreensivos, fazendo uma integração do transcendente com o real, ordenando-o e dando significação a sua existência. A memória coletiva assume o lugar, na vida em sociedade, da memória individual. O indivíduo,

28 BARREIRA, op. cit., p. 41.

29 Ibid., p. 43.

30 Ibid., p. 45. 
no exercício de memória, sempre se apóia na memória do grupo. O fato de pertencer a diversos grupos faz com que o indivíduo também pertença a diversas correntes de memórias. Isso significa que o pensamento individual reflete esses pontos de vista. A reconstituição do passado apóia-se nas consciências coletivas das quais o indivíduo fez parte.

\section{Identidade no Protestantismo}

Rubem Alves encara o Protestantismo a partir de uma perspectiva pluralizante: protestantismos. Para ele, a grande questão ao tentar estabelecer uma identidade ao Protestantismo é o fato de não haver um critério unificador. Não há uma unidade estrutural, não há um centro em torno do qual se é possível integrar as muitas faces do Protestantismo:

\footnotetext{
Faces são sempre máscaras. Elas revelam, mas também escondem. É o que ocorre com as faces do Protestantismo. Seitas e denominações, organizações e movimentos são princípios internos de organização. Mas a organização interna de uma instituição, por mais interessante que seja, pouco ou nada nos revela de sua significação real. ${ }^{31}$
}

Em toda a América Latina, o Protestantismo tem sua identidade mais reforçada em termos de oposição ao catolicismo. A identidade protestante se firma mais na ótica negativista. E essa oposição sustenta-se a partir de conjuntos doutrinários, sejam protestantes ou católicos; em espaços, que podem ser profanos ou sagrados; e em valores, que apontam para um juízo sobre o bem e o mal. A identidade protestante no Brasil não é identidade de afirmação, mas ao contrário, pode ser entendida como negativa e exclusivista. Não admite outras possibilidades; no máximo, por conveniência, suporta.

A possibilidade de identificar o Protestantismo no Brasil e, por conseqüência, estabelecer caminhos para uma reflexão sobre a identidade dos

31 ALVES, Rubem. Dogmatismo e tolerância. São Paulo: Paulinas, 1982. p. 80. 
grupos mais tradicionais, longe de uma unidade doutrinal/estrutural, perpassa a ótica da síntese de idéias numa tentativa de construção de identidade pela visão de mundo, pelas categorias globais de relacionamentos, de delimitação do espaço sagrado e profano e pelo antagonismo ao catolicismo.

Quanto à possibilidade de análise do Protestantismo por síntese de idéias $^{32}$, podemos verificar essa metodologia em vários pesquisadores do Protestantismo: Antonio Gouvêa Mendonça, Procoro Velásquez, Israel Belo de Azevedo, Elter Dias Maciel, Rubem Alves, Jean-Pierre Bastian, Simei Monteiro, Paulo Barreira, Otto Maduro, Émile G. Leonard. Embora com interesses e orientações diversas, essa classificação, além de estabelecer-se como uma metodologia possível, apresenta um núcleo comum bem semelhante.

Rubem Alves ${ }^{33}$ adota as seguintes categorias de visão de mundo, ideologia, práticas e motivação no Protestantismo Brasileiro:

1. Ideal Missionário: A ordem maior a qual cabe o cristão obedecer: converta o mundo nessa geração para Cristo. O motor do movimento missionário, segundo Rubem Alves: "Construir Igrejas, construir escolas, construir hospitais: curar a alma, curar a mente, curar o corpo". ${ }^{34}$

2. Oposição ao Catolicismo: A identidade protestante depende demais do catolicismo. Para se afirmar, este (protestantismo) tem de o fazer em oposição àquele (catolicismo). Com esse viés, o catolicismo é visto como símbolo de atraso, de idolatria, enquanto que o protestantismo é o inverso: progresso, firmeza doutrinária, etc;

3. Conversão marcada por um novo estilo de vida: Este novo estilo tem o seu fundamento no axioma bíblico usado para firmar a estratégia missionária: "Todos os homens pecaram; o salário do pecado é a morte; estamos destinados 'à perdição eterna, não há nada que possamos fazer para nos livrar desta

32 Categorias como visão de mundo, compreensão de sagrado e profano, infusões do pietismo, fundamentalismo, puritanismo, etc. Algumas dessas categorias já foram mencionadas no capítulo sobre o Protestantismo no Brasil.

33 ALVES, op. cit., p. 60.

34 Ibid., p. 60-61. 
situação; Deus, pelo seu amor, nos salva gratuitamente, se nos entregarmos de corpo e alma 'à misericórdia de Cristo". ${ }^{35}$ Diferentemente do Calvinismo, que associava o novo estilo de vida ao sucesso financeiro, no Brasil esse estilo de vida se associa a um virtuosismo moral: "Os crentes são diferentes... estilo de vida ímpar... disciplinado, não fumavam, não bebiam, não jogavam, eram honestos, fiéis às esposas, guardavam o domingo com rigor" ${ }^{36}$

4. Fundamentalismo: "O Protestantismo sentiu uma grande tendência para uma definição cerebral do que significa ser cristão”. ${ }^{37}$ A fé passou a ser entendida como uma adesão intelectual a um corpo doutrinário, devidamente abalizado pelas Sagradas Escrituras. A grande questão é que o fundamentalismo, uma vez estabelecendo esse paradigma, traz a reboque a idéia de que atingindo um consenso sobre a expressão intelectual da fé, terminam todas as dúvidas. ${ }^{38}$

5. Mundo estável e fixo: O mundo é estável, dominado por certezas. Todos os que fazem parte deste mundo vêem suas dúvidas acabadas, e as possíveis dúvidas levantadas o são por incrédulos, pecadores, opositores da verdade.

6. Espírito de conservadorismo: Se a verdade última já foi dada aos homens no passado, basta-nos apenas conservá-la e anunciá-la. $^{39}$

7. Doutrina social bem delimitada: Expressada pela conhecida frase: Converta-se o homem e a sociedade se converterá.

Mesmo usando nomenclaturas diferentes/semelhantes ou agrupando-as em categorias maiores, é possível verificar, pelo menos na configuração de visão de mundo, moralidade, sociedade, estilo de vida, um núcleo comum. As afirmações de Halbwachs de correntes de memórias que se entrecruzam são perfeitamente verificáveis nas expressões brasileiras do Protestantismo. Há uma base sob a qual os protestantes se identificam no

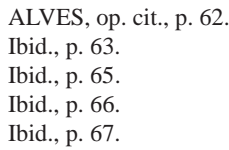


Brasil, seja de forma negativa - oposição ao Catolicismo -, ou de outra forma, algumas vezes revelando sua face fundamentalista.

Uma questão que pede definição é: de que maneira os conceitos sobre memória coletiva, e correntes de memória, podem, de alguma maneira, nos fornecer pistas para a tentativa de reconhecer caminhos usados pela instituição para não apenas definir qual seja a sua identidade, mas articular os seus conceitos em relação à comunidade na qual quer reforçar essa identidade. Além disso, levando em consideração esse mesmo contexto, de que maneira a comunidade articula-se quando envolvida em suas correntes de memória, como se define? E ainda: como atualiza sua identidade, e a partir de qual referencial? Uma vez que a memória não tem sentido fora da existência, possivelmente a construção de visão de mundo e sua relação com o transcendente possam (nos) fornecer algumas pistas.

\section{Considerações finais}

Clifford Geertz ${ }^{40}$ sustenta que a religião nunca é apenas metafísica, mas em todos os povos suas formas e objetos de culto estão profundamente interligados com a questão moral. Aquilo que se refere ao "além do mundo” tem implicações profundas com o dever, com a orientação da conduta humana. Numa perspectiva antropológica, os aspectos morais e elementos valorativos $^{41}$ de uma determinada cultura foram resumidos, designados sob o termo ethos, enquanto os aspectos cognitivos e existenciais foram designados pelo termo visão de mundo:

O ethos de um povo é o tom, o caráter e a qualidade de sua vida, seu sentido moral e estético e sua disposição, é a atitude subjacente em relação a ele mesmo e ao seu mundo que a vida reflete. A visão de mundo que esse povo tem é o quadro que elabora das coisas como elas são na simples realidade, seu

40 GEERTZ, Clifford. A interpretação das culturas. Rio de Janeiro: Guanabara Koogan, 1989.

41 Ibid., p. 143. 
conceito da natureza de si mesmo, da sociedade. Esse quadro contém suas idéias mais abrangentes sobre a ordem. ${ }^{42}$

(É, ainda) Na perspectiva de Geertz, é essencial para a expressão religiosa a demonstração significativa entre os valores que o povo conserva e a ordem geral da existência onde ele mesmo se encontra:

O ethos torna-se intelectualmente razoável porque é levado a representar um tipo de vida implícito no estado de coisas real que a visão do mundo descreve, e a visão do mundo torna-se emocionalmente aceitável por se apresentar como imagem de um verdadeiro estado de coisas do qual esse tipo de vida é expressão autêntica. ${ }^{43}$

As análises que tentam descrever as atividades morais, estéticas e outras atividades normativas, em termos de teorias baseadas não na observação de tais atividades, mas apenas em considerações lógicas estão em declínio:

A abordagem de uma teoria de valor que olhe o comportamento de pessoas reais, em sociedades reais, vivendo em formas de culturas reais procurando tanto seu atributo como sua validade, irá afastar-nos dos argumentos abstratos e muito escolásticos nos quais um número limitado de posições clássicas é repetido sempre e sempre, com muito pouca novidade a recomendá-los. ${ }^{44}$

A “armazenagem” dos significados só pode se dar através de símbolos. É a partir desses símbolos que se tem a formulação legal, a força que leva o "fiel" a conhecer o seu mundo, a qualidade de vida emocional que ele suporta, e a maneira como deve comportar-se nele:

42 GEERTZ, op. cit., p. 144.

43 Id.

44 Ibid., p. 159. 
Dessa forma, os símbolos sagrados relacionavam uma ontologia e uma cosmogonia com uma estética e uma moralidade: seu poder peculiar provém de uma suposta capacidade de identificar o fato com o valor no seu nível mais fundamental, de dar um sentido normativo abrangente àquilo, que, de outra forma, seria apenas real. ${ }^{45}$

Os símbolos sagrados, portanto, não podem deixar de ser entendidos em tudo o que se propõe, pois são eles que formam um sistema religioso:

\begin{abstract}
Para aqueles comprometidos com eles, tal sistema religioso parece mediar um conhecimento genuíno, o conhecimento das condições essenciais nos termos dos quais a vida tem que ser necessariamente vivida. Particularmente onde esses símbolos não são criticados, histórica ou filosoficamente, como acontece na maioria das culturas do mundo, os indivíduos que ignoram as normas moral-estéticas que os símbolos formulam, que seguem um estilo de vida discordante, são vistos não tanto como maus, mas como estúpidos, insensíveis, ignorantes ou, em casos de infrações extremas, como loucos. ${ }^{46}$
\end{abstract}

É ainda importante notar que a espécie de símbolos (ou complexos de símbolos) que os povos vêem como sagrada varia muito (amplamente). Um símbolo ou conexão de múltiplos símbolos pode constituir os meios principais através dos quais uma síntese de vida, visão de mundo, ordenamento da realidade se expressa. Se os símbolos, como diz Geertz, são estratégias para englobar situações, então precisamos dar mais atenção a como, no Protestantismo, as pessoas os articulam nas suas muitas relações sociais, e no entremeio das correntes de memória, que constituemapóiam sua identidade. 